\title{
The Use of Volatile Inhibitors to Suppress Corrosion of Metals in the Atmosphere of Livestock Buildings
}

\author{
L E Tsygankov*1, , V I Vigdorovich ${ }^{1}$, A N Dorokhova ${ }^{1}$, L G Knyazeva ${ }^{1}$, A V Dorokhov² and A A Uryadnikov ${ }^{2}$ \\ ${ }^{1}$ All-Russian Scientific Research Institute of Use of Machinery and Oil Products, Tambov State Technical University, Tambov, Russia
}

${ }^{2}$ Derzhavin State University, Tambov, Russia

Received: January 04, 2018; Published: January 25, 2018

*Corresponding author: L E Tsygankov, All-Russian Scientific Research Institute of Use of Machinery and Oil Products, Derzhavin State University, Tambov, Russia, Tel: 74752723655; Email: vits21@mail.ru

\section{Abstract}

At room temperature, the protective efficacy of the volatile inhibitors (VIC) "IFHAN-A" (A-112, 114 and 118) was studied under atmospheric corrosion of carbon steel St3, brass L62 and copper $\mathrm{M}_{2}$ in the presence of corrosion stimulants (CS) in the air: $\mathrm{CO}_{2}((0.2-0.6)$ vol. \%); $\mathrm{H} 2 \mathrm{~S}((10-$ $\left.30) \mathrm{mg} / \mathrm{m}^{3}\right) ; \mathrm{NH}_{3}((20-60) \mathrm{mg} / \mathrm{m} 3)$ and $100 \%$ relative humidity, which simulates the atmosphere of livestock buildings. In the case of carbon steel in the presence of a binary mixture of CSs: $\mathrm{CO}_{2}+\mathrm{NH}_{3}, \mathrm{CO}_{2}+\mathrm{H}_{2} \mathrm{~S}$ and $\mathrm{NH}_{3}+\mathrm{H}_{2} \mathrm{~S}$, the protective action of the VIC is between 67 and $95 \%$. When corrosion of brass and copper, the protective capacity of IFHAN-112 and IFHAN-118 decreases accordingly to 10 (Cu, IFHAN-112, NH3 + $\mathrm{H}_{2} \mathrm{~S}$ ) and 13 (brass, IFHAN-118, $\mathrm{CO}_{2}+\mathrm{H}_{2} \mathrm{~S}$ ) \% or $30 \%$ (brass, IFHAN-118, $\mathrm{NH}_{3}+\mathrm{H}_{2} \mathrm{~S}$ ). These VIC stimulate copper corrosion in the presence of a binary mixture $\left(\mathrm{CO}_{2}+\mathrm{H}_{2} \mathrm{~S}\right)$. Only in the presence of IFHAN-114, the protective effect does not decrease below $74 \%$.

Key words: Steel; Copper; Brass; Corrosion; Hydrogen Sulphide; Carbon Dioxide; Ammonia, Volatile Inhibitors; Protection.

\section{Introduction}

Earlier in a number of works [1-3] we showed the high efficiency of volatile inhibitors (VIC) against metal corrosion in conditions of agricultural production. This is typical both in the absence of heightened concentration of corrosion stimulants (CS) $\mathrm{CO}_{2}, \mathrm{H}_{2} \mathrm{~S}$ and $\mathrm{NH}_{3}$ in the atmosphere of industrial premises as compared with the background and with their separate presence [1-3]. At the same time, VICs are able to exert a significant negative impact under similar conditions. In particular, the presence of the volatile inhibitor IFHAN-8 causes intense corrosion cracking of brass L62 [3]. Thus, in each specific case, a complex of studies is required to assess the feasibility of using a particular LIC in specific atmospheric conditions in agricultural premises. It should be taken into account that such atmospheres are characterized by the presence in the air of not one, but at the same time two or all three corrosion stimulants. Such a situation can have a significant impact on the protective effectiveness of the VIC. The fact is that the interaction of stimulants of corrosion can be not only additive. It is possible both the synergism of the influence of the CSs, that is, the strengthening of their mutual negative impact, and the pronounced antagonism, which, undoubtedly, can affect the protective ability of the VIC. In addition, the presence of CSs in the surface phase film of moisture responsible for the corrosion of structural materials can lead to their chemical interaction, for example, according to the reaction: $\mathrm{CO}_{2}+2 \mathrm{NH}_{3}+\mathrm{H}_{2} \mathrm{O} \rightarrow\left(\mathrm{NH}_{4}\right)_{2} \mathrm{CO}_{3}$, Which can also affect the kinetics of electrode reactions and corrosion of metals, as a whole.

The purpose of this work is to study the effectiveness of a number of volatile corrosion inhibitors of the "IFHAN" series in the conditions of corrosion of carbon steel, brass and copper in atmosphere simulating it in livestock buildings containing simultaneously two of three above mentioned corrosion stimulants or all three CSs at their fixed concentrations and relative humidity (H) of air equal to or close to $100 \%$. The content of CSs corresponded to the maximum permissible one by regulatory documents for livestock buildings $[4,5]$. or exceeded them three times. The normatively permissible concentration of the studied corrosion stimulators for cattle-breeding premises (MPC) has the following values [4]. $\mathrm{NH}_{3}-20 \mathrm{mg} / \mathrm{m}^{3}, \mathrm{H}_{2} \mathrm{~S}-10 \mathrm{mg} / \mathrm{m}^{3}, \mathrm{CO}_{2}$ - not standardized. In this paper, for $\mathrm{CO}_{2}$ content it is assumed to be equal to $0.2 \%$ by volume. The relative humidity of air in all experiments is $100 \%$.

\section{Experimental}

For the conduct of corrosion tests, samples of steel St3 (chemical composition, wt.\%: C- 0.20, Mn-0.51, Si- 0.15, P-0.04, S-0.05, Cr-0.32, Ni-0.21, Cu-0.23, Fe-98.29), copper M2 (chemical composition, wt.\%: $\mathrm{Al} \leq 0.002 ; \mathrm{Zn} \leq 0.005 ; \mathrm{Mn} \leq 0.01 ; \mathrm{Cr} \leq 0.05 ; \mathrm{Si}$ $\leq$ 0.01; $\mathrm{Ir} \leq 0.05 ; \mathrm{Cu}-99.7)$ and two-phase $(\alpha+\beta)$ brass (chemical 
composition, wt.\%: Zn-22.5; Mn-29.0; Fe-2.0; Al-4.1; Cu-rest) in size $30 \times 25 \times 3 \mathrm{~mm}$ prepared according to the 6th class of purity were used. As VIC studied developed in the A.N. Frumkin Institute of Physical Chemistry and Electrochemistry of RAS (IPhChE RAS), inhibitors of corrosion: IFHAN - 8 (amino alcohol), IFHAN - 112 (mixture inhibitor based on benzotriazole), IFHAN - 114 (nonequimolar mixture of polyamine and weak organic acid) and IFHAN - 118 (dimethylbenzylamine salt). Corrosion tests were carried out at room temperature in hermetically sealed desiccators (main container) with a volume of 7 liters in two versions. In the first one, the atmosphere was saturated with only two corrosion stimulators $\left(\mathrm{CO}_{2}+\mathrm{NH}_{3}, \mathrm{CO}_{2}+\mathrm{H}_{2} \mathrm{~S}\right.$ or $\left.\mathrm{H}_{2} \mathrm{~S}+\mathrm{NH}_{3}\right)$, in the second variant all three stimulators were used. Concentrations of CS are indicated in the text. In the main container (Em) additional (Ead) one was placed, in which there was used VIC (10-15 г). Vessels with dilute solutions in which CS synthesis reactions passed were outside the desiccators, and the obtained CSs were sent to Em by means of hoses injected through the hole in its cover. The hoses were provided with overlapping valves.

To create the necessary equilibrium CS concentration in the gas phase, a special technique was developed that allows one to calculate the amount of initial substances necessary for the synthesis of CSs on base of the specified partial pressure of the CSs in the gas phase and their equilibrium concentrations in the liquid [6] using Henry's law. The solubility of the CSs studied in water as a function of temperature and the partial pressure in the gas phase was borrowed in [7]. To obtain CSs in the laboratory, the following reactions were used:

$$
\begin{aligned}
& \mathrm{Na}_{2} \mathrm{~S}+2 \mathrm{HCl} \rightarrow \mathrm{H}_{2} \mathrm{~S}+2 \mathrm{NaCl} \\
& \mathrm{Na}_{2} \mathrm{CO}_{3}+2 \mathrm{HCl} \rightarrow 2 \mathrm{NaCl}+\mathrm{CO}_{2}+\mathrm{H}_{2} \mathrm{O} \\
& \mathrm{NH}_{4} \mathrm{Cl}+\mathrm{KOH} \rightarrow \mathrm{NH}_{3}+\mathrm{KCl}+\mathrm{H}_{2} \mathrm{O} .
\end{aligned}
$$

In desiccators, samples of metals were hanged up on special supports on nylon threads. The duration of the corrosion tests was 240 hours. Corrosion products after the completion of the experiments were removed with a $10 \% \mathrm{HCl}$ solution containing an additional $1 \mathrm{~g} / \mathrm{L} \mathrm{KI}$ and $3 \mathrm{~g} / \mathrm{L}$ hexamethylenetetramine as a mixed contact inhibitor.

The protective effect of the inhibitors $(\mathrm{Z}, \%)$ was estimated by the formula:

$$
Z, \%=100\left(K_{\mathrm{o}}-K_{I n h}\right) / K_{\mathrm{o}}
$$

Where $\mathrm{K}_{0}$ and $\mathrm{K}_{\mathrm{Inh}}$ are corrosion rates in the absence and in the inhibitor presence respectively.

\section{Results and discussion}

Corroding in the atmosphere, metal structural material is almost always covered with a surface adsorption $(\mathrm{H} \leq 70 \%)$ or phase $(80 \leq \mathrm{H} \leq 100 \%)$ moisture film [6]. whose thickness in the latter case can reach hundreds of microns. It absorbs corrosion stimulators, which are partially hydrated in it and are adsorbed on the metal surface in the hydrated state or in the form of electrolytic dissociation products. This leads to a change in the double electric layer arising at the metal/liquid interface, stimulation of partial electrode reactions and, ultimately, acceleration of corrosion of metals. At the same time, in such surface films, active VIC molecules are absorbed, which are then adsorbed on the corroding surface, inhibiting the cathodic or anodic reaction of corrosion process, or both. Let's consider cases both when concentration of CSs three times exceeds normatively admissible one, and completely corresponds to the admissible values.

\section{Carbon Steel}

Initially consider the results of gravimetric measurements obtained in the presence of simultaneously $\mathrm{CO}_{2}$ and $\mathrm{NH}_{3}$. When their concentration exceeds the normatively admissible values three times in the absence of the VIC, the rate of the total corrosion of the steel is of the order of $0.01 \mathrm{~g} /(\mathrm{m} 2 \bullet \mathrm{h})$. Its value occupies an intermediate position in comparison with $\mathrm{K} 0 \mathrm{i}$ in the presence of only $\mathrm{NH}_{3}$ or $\mathrm{CO}_{2}$ :

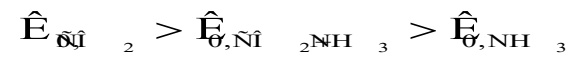

Corrosion has a pronounced local character with ulcerous formations on the surface of the metal. Data on the protective efficacy of all the VIC studied are shown in Table 1.

Table 1: Protective efficiency $(\mathrm{Z}, \%)$ of the studied VIC in relation to the corrosion of steel in the presence of simultaneously two corrosion stimulators in the air. The numerator is $\mathrm{Z}$ for the threefold excess of the maximum permissible concentration of CSs in the air, the denominator is Z for the CS concentration corresponding to the MPC.

\begin{tabular}{|c|c|c|c|}
\hline \multirow{2}{*}{ VIC } & \multicolumn{3}{|c|}{$\mathrm{Z}$ in the Presence of CSs } \\
\cline { 2 - 4 } & $\mathbf{C O}_{\mathbf{2}}+\mathbf{N H}_{\mathbf{3}}$ & $\mathbf{C O}_{\mathbf{2}}+\mathbf{H}_{\mathbf{2}} \mathbf{S}$ & $\mathbf{H}_{\mathbf{2}} \mathbf{S}+\mathbf{N H}_{\mathbf{3}}$ \\
\hline IFHAN - 112 & $76 /-$ & $81 /-$ & $70 /-$ \\
\hline IFHAN - 114 & $86 / 87$ & $94 / 100$ & $83 / 85$ \\
\hline IFHAN - 118 & $85 /-$ & $81 /-$ & $67 /-$ \\
\hline
\end{tabular}

Here Table 1 If there are $\mathrm{CO}_{2}$ and $\mathrm{NH}_{3}$ in the air, IFHAN-114 is the most effective. In its presence, the corrosion of steel is uniform, without traces of local surface lesions. If both $\mathrm{CO}_{2}$ and $\mathrm{H}_{2} \mathrm{~S}$ are present simultaneously in the uninhibited gas phase and their concentration exceeds the normatively admissible values three times, the rate of total steel corrosion is $0.07(\mathrm{~g} / \mathrm{m} 2 \bullet \mathrm{h})$, and the corresponding row is:

$$
\hat{\mathrm{E}}_{\mathrm{O}, \mathrm{CO} 2}>\hat{E}_{\mathrm{O}, \mathrm{CO}_{2}+\mathrm{H}_{2} \mathrm{~S}}>\hat{\mathrm{E}}_{\mathrm{O}, \mathrm{H}_{2} \mathrm{~S}}
$$

An intensive local lesion of the metal surface with intensive pitting is again observed. The protective effect of VICs is quite high (Table 1), but in the presence of IFHAN-118, pitting is observed again. . Inhibitors of IFHAN-112 and IFHAN-114 prevent it. Let's note one more row, taking place,

$$
Z_{\mathrm{CO}_{2}}>Z_{\mathrm{H}_{2} \mathrm{~S}}>Z_{\mathrm{CO}_{2}+\mathrm{H}_{2} \mathrm{~S}}
$$

Where in the lower index the nature of corrosion stimulants present in the air is indicated. It can be assumed that the protective effect of the " $\mathrm{FeCO}_{3}+\mathrm{FeSn}+$ inhibitor" system is lower than "FeCO + inhibitor" and "FeSn + inhibitor" ones, but still remains relatively high. Again, IFHAN-114 is most effective. If both NH3 and $\mathrm{H} 2 \mathrm{~S}$ are present simultaneously in the uninhibited gas phase and their concentration exceeds the normatively admissible values three times, the rate of total steel corrosion is $0.03(\mathrm{~g} / \mathrm{m} 2 \bullet \mathrm{h})$ and pronounced local destruction of metal surface is observed. 
Consequently, equipment made of carbon steel cannot be left without effective protection under similar conditions. The row observed in this case has the form:

$$
\mathrm{K}_{0, \mathrm{H} 2 \mathrm{~s}}>\mathrm{K}_{0, \mathrm{H} 2 \mathrm{~s}}+\mathrm{NH}_{3}>\mathrm{K}_{0, \mathrm{NH} 3}
$$

The protective efficacy of the studied VIC in this atmosphere is shown in Table 1. In the presence of IFHAN-114, it is the highest, and the value of $\mathrm{Z}$ of IFHAN-118 is markedly lowered (Table 1). Due to the fact that IFHAN-114 is the most effective of the inhibitors studied, tests in air media with a normatively permissible concentration of corrosion stimulators were conducted only in its presence, especially since this VIC possesses the lowest saturated vapor pressure (below 10-3 mm $\mathrm{Hg}$ or $<0.133 \mathrm{~Pa}$ ). Consequently, it is characterized by the lowest concentration of Table 2: Protective efficiency $(\mathrm{Z}, \%)$ of the studied VIC in the presence of simultaneously two corrosion stimulators in the air. The numerator is $\mathrm{Z}$ for the threefold excess of the MPC of CSs in the air, the denominator is $\mathrm{Z}$ for the CS concentration corresponding to the MPC.

\begin{tabular}{|c|c|c|c|c|}
\hline \multirow{2}{*}{ VIC } & \multirow{2}{*}{ Metal } & \multicolumn{3}{|c|}{ Z in the presence of CSs } \\
\cline { 2 - 4 } & & $\mathbf{C O}_{2}+\mathbf{N H}_{3}$ & $\mathbf{C O}_{2}+\mathbf{H}_{2} \mathbf{S}$ & $13 /-$ \\
\hline IFHAN - 112 & Brass & $75 /-$ & Stimulation $/-$ & $75 /-$ \\
\hline IFHAN - 114 & Copper & $85 /-$ & $75 / \sim 100$ & $70 /-$ \\
\hline IFHAN - 118 & Brass & $82 / 74$ & $75 / \sim 100$ & $30 / 90$ \\
\hline & Copper & $79 / 95$ & $13 /-$ & $84 /-$ \\
\hline
\end{tabular}

\section{Copper and Brass}

In an atmosphere containing $0.6 \mathrm{vol} \% \mathrm{CO}_{2}$ and $60 \mathrm{mg} / \mathrm{m}^{3} \mathrm{NH}_{3}$ (hereinafter, if not specifically stated, the concentration of CSs is raised threefold relative to the normally permissible at $\mathrm{H}=100 \%$ ) in the absence of VIC, the overall corrosion rate of brass and copper are 0.010 and $0.014-0.020 \mathrm{~g} /\left(\mathrm{m}^{2} \bullet \mathrm{h}\right)$ respectively. Corrosion has a weakly expressed local character (small rare pittings) with a darkening of a significant portion of the surface as a result of the formation of $\mathrm{CuO}$ film on it. Here Table 2 It is easy to see that under the conditions under consideration all the VICs are characterized by a close efficiency, and the darkening of the metal surface, due to the formation of copper (II) oxide on the surface, is practically not observed, as well as traces of local damage to the metal surface. In the presence of $\mathrm{CO}_{2}$ and $\mathrm{H} 2 \mathrm{~S}$ in the air, both corrosion stimulators are acidic. Carbonic acid formed by the reaction $\mathrm{CO}_{2}+\mathrm{H}_{2} \mathrm{O} \leftrightarrow$ $\mathrm{H} 2 \mathrm{CO} 3$, is noticeably stronger than hydrogen sulphide one, which, in principle, should lead to a $\mathrm{pH}$ value in the surface phase film of moisture of the order of 5.6-5.8. With the simultaneous presence of these CSs in the gas phase, a darkening of $\sim 25 \%$ of the brass surface is observed, but the corrosion is uniform. In the presence of volatile inhibitors IFHAN-112 and IFHAN-118, the protective effect is reduced to $13 \%$, and stimulation of the copper corrosion is observed. And IFHAN-118 causes a significant deterioration in the state of the surface of brass. The same holds for copper. Only IFHAN-114 retains a relatively high protective efficiency with respect to both metals $(\mathrm{Z}=75 \%$, Table 2$)$.

In the atmosphere with the simultaneous presence of $\mathrm{H}_{2} \mathrm{~S}$ and $\mathrm{NH}_{3}$ at $\mathrm{H}=100 \%$ with corrosion of brass, the protective efficiency of IFHAN-112 and IFHAN-114 reaches 75\%, and IFHAN-118 - even saturation in the air, which is important for ecological reasons, and the lowest consumption coefficient. With a decrease in the concentration of corrosion stimulators to the normative value for livestock premises, the protective effect of the IFHAN-114 is slightly increased, and to the greatest extent in the presence of $\mathrm{CO}_{2}$ and $\mathrm{H}_{2} \mathrm{~S}$ (Table 1). The evaluation of the efficiency of VIC in atmospheres containing simultaneously all three corrosion stimulators is of undoubted interest. In this case, one could expect both a synergistic (increase in the value of $\mathrm{Z}$ ) and antagonistic effects. When the micro components are present in a concentration of $0.6 \mathrm{vol} \% \mathrm{CO}_{2}+60$ $\mathrm{mg} / \mathrm{m}^{3} \mathrm{NH}_{3}+30 \mathrm{mg} / \mathrm{m}^{3} \mathrm{H}_{2} \mathrm{~S}$, the protective effect of IFHAN-114 is $95 \%$. With a decrease in their content to the normally permissible value, the value of $\mathrm{Z}$ remains practically at the same level.
$84 \%$. For copper, the value of $\mathrm{Z}$ in the presence of all the inhibitors is sharply reduced. Because of the great versatility of the action of the IFHAN-114, further studies in the presence of CSs in the atmosphere with a concentration equal to MPC were carried out only with IFHAN-114. A threefold decrease in CS concentration markedly increases the protective effect of this VIC (Table 2). Some decrease in the value of $\mathrm{Z}$ is observed only for brass in the presence of $\mathrm{CO}_{2}$ and $\mathrm{NH}_{3}$. Nevertheless, the rate of corrosion can be reduced by almost 4 times. It should be borne in mind that this is the most likely option for the presence of corrosion stimulators in the atmosphere of livestock buildings. Here Table 3 According to the obtained experimental data, even in this case, with the content of CSs in air equal to 3 MPC, IFHAN-114 remains the most effective of the studied VICs. Therefore, when the concentration of CSs was lowered threefold, only its protective effect was evaluated. It was higher than in the presence of the $\mathrm{NH}_{3}+\mathrm{H}_{2} \mathrm{~S}$ binary system, and comparable with the influence of IFHAN-114 in the remaining binary systems of $\mathrm{CO}_{2}+\mathrm{NH}_{3}$ and $\mathrm{CO}_{2}+\mathrm{H}_{2} \mathrm{~S}$ stimulants.

Table 3: Protective efficiency $(Z, \%)$ of the studied VIC in the presence of simultaneously three corrosion stimulators in the air. The numerator is $Z$ for the threefold excess of the MPC of CSs in the air; the denominator is $Z$ for the CS concentration corresponding to the MPC.

\begin{tabular}{|c|c|c|}
\hline \multirow{2}{*}{ VIC } & \multicolumn{2}{|c|}{ Z of VIC for } \\
\cline { 2 - 3 } & Brass & Copper \\
\hline IFHAN - 112 & $56 /-$ & $90 /-$ \\
\hline IFHAN - 114 & $96 / 60$ & $95 / 99$ \\
\hline IFHAN - 118 & $44 /-$ & $88 /-$ \\
\hline
\end{tabular}




\section{Conclusion}

The influence of nature and the concentration of corrosion stimulators significantly affect the effectiveness of the studied VICs. Most effective inhibitor of steel corrosion is IFHAN-114, the protective effect of which, depending on the nature of the binary system of CSs is in the range of $83 \mathrm{CH}_{2} \mathrm{~S}$ and $\mathrm{NH}_{3}$ with a concentration equal to $3 \mathrm{MPC})-100\left(\mathrm{CO}_{2}\right.$ and $\mathrm{H}_{2} \mathrm{~S}$ with a concentration equal to the MPC)\%. At corrosion of brass and copper in the presence of $\mathrm{CO}_{2}$ and $\mathrm{NH}_{3}$ all the VICs are characterized by a close efficiency which is not less than $74 \%$. Replacement of $\mathrm{NH}_{3}$ with $\mathrm{H}_{2} \mathrm{~S}$ significantly reduces the protective efficacy of IFHAN-112 and IFHAN-118. A similar picture is also observed in the presence of simultaneously $\mathrm{H}_{2} \mathrm{~S}$ and $\mathrm{NH}_{3}$ for copper. For brass, the effectiveness of these inhibitors remains at least is not less than 75\%. Only IFHAN-114 in all cases is characterized by a high protective effect. In the presence of simultaneously all three corrosion stimulators with their content in air equal to the MPC, IFHAN-114 is highly effective in corrosion of all the studied metallic materials ( $\mathrm{Z}$ reaches $95-99 \%$, decreasing only in the case of brass up to $60 \%$ ).

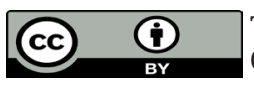

This work is licensed under Creative Commons Attribution 4.0 License

Submission Link: http://biomedres.us/submit-manuscript.php

\section{References}

1. Vigdorovich VI, Knyazeva L G, Zazulya AN, Kuznetsova EG, Andreev NN, et al. (2016) Application of IFHAN-118 volatile inhibitor to protect agricultural equipment against atmospheric corrosion. Russ Agric Sci 42(2): 65-68.

2. Vigdorovich VI, Knyazeva LG, Zazulya AN, Prokhorenkov VD, Kuznetsova EG, et al. (2017) Use of the IFKhAN Type of Volatile Inhibitors for Protection of Steel Equipment in the Atmosphere of the Livestock Premises. Russ Agric Sci 43(2): 184-187.

3. Vigdorovich VI, Knyazeva LG, Zazulya A N, Prokhorenkov V D, Kuznetsova E G, et al. (2017) Suppression of Atmospheric Corrosion of Brass Using Volatile Inhibitors. Russ Agric Sci 43(4) 342-346.

4. Onegov AP, Yarabustovskii IF, Chernykh VI (1977) Gigiena sel'skokhozyaistvennykh zhivotnykh (Hygiene of Agricultural Animals) Moscow: Kolos.

5. Kuz'min VN, Fedorenko VF, Sazonov SN (2013) Spravochnik fermera (Farmer's Handbook), Moscow: Rosinformagrotekh.

6. Rozenfel'd I L (1985) Atmospheric corrosion of metals. Moscow: Nauka.

7. Nekrasov, BV Perel'man VI (Eds) (1956) Kratkii spravochnik khimika (Chemist's Short Reference Book), Moscow: GNTI khimicheskoi literature.

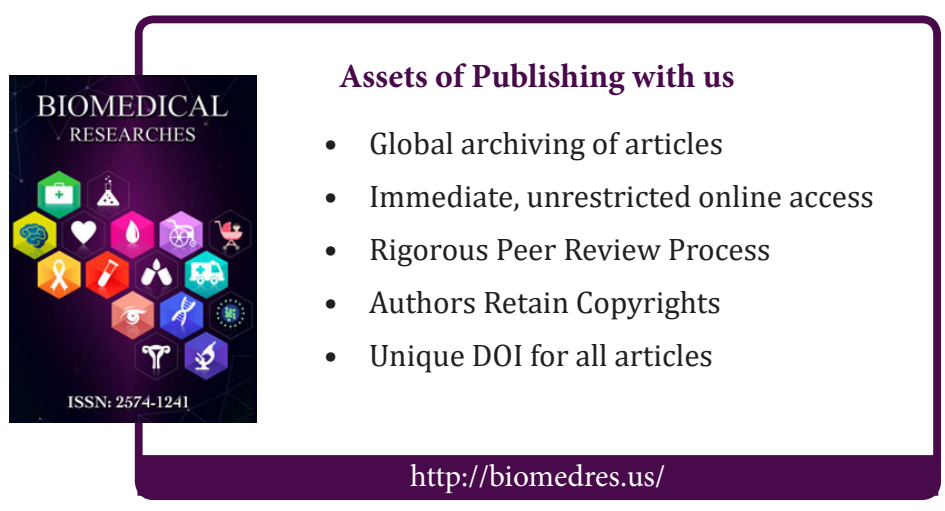

